\title{
Benchmarking of the Professional Education System in Postsecondary Institutions of the Russian Federation
}

\author{
Elena N. Krolevetskaya ", Elena I. Eroshenkova, Iliya F. Isaev, Natalia L. Shekhovskaya, \\ Irina V. Irkhina, Elena A. Karabutova \\ Belgorod State University, Russia
}

Received July 22, 2019; Revised September 21, 2019; Accepted September 30, 2019

Copyright $\odot 2019$ by authors, all rights reserved. Authors agree that this article remains permanently open access under the terms of the Creative Commons Attribution License 4.0 International License

\begin{abstract}
In this article, the concept "benchmarking of the professional education system" is addressed as the information and management system analysis concerning the activities of the best postsecondary professional institutions (PSPI), and the management methods in the development of professional education system. The research method is benchmarking that allows the authors to determine methods, forms, technologies of educational activities, and management methods. Results reveal that the National Competition, "The best project of the professional education system modeling" leads to finding the best professional education system models developed by PSPI according to the principles of a project-based approach.
\end{abstract}

Keywords Benchmarking, Professional Education System, Postsecondary Professional Institution (PSPI), Project-based Approach

\section{Introduction}

In circumstances of modern education competitive environment, a postsecondary professional institution can be developed effectively just in case of being oriented to the most desirable educational practice. The best approach to develop the definite postsecondary institution is investigating "best practices" and the achievements of leading professional education institutions, afterward comparing and implementing the activity results. This process is economically understood as benchmarking. Benchmarking is becoming a global phenomenon at present and is regarded as a mechanism that assists organizations around the world in sharing the knowledge and experience to advance [Kurdyumova, 2011; Malamiri, et al 2016]. Benchmarking in education occurs when measurable standards are set for learning. For instance, benchmarks might be set for the concepts that must be mastered in each grade. They might also be employed to recognize where a particular student, class, or even school ranks compared to others. Benchmarking in education should be about discovering the place of standing, and learning about the existence and the acts to be performed by observing those around. Benchmarking should not imply to fomenting panics about performance regarding overseas competitors. It is necessary to adopt a successful track record in professional training to optimize the educational activities of any postsecondary professional institution. In this respect, this investigation studies the benchmarking of the professional education system in postsecondary institutions of the Russian Federation.

\section{Methodology}

In this research, the benchmarking method has been used. Benchmarking is the process of comparing and measuring an organization against others anywhere in the world, to better understand the measures, performance, and practices so that they can rapidly improve the route to world-class performance.

Benchmarking in the professional education system is the information and management system analysis concerning the activities aspects of the most successful training postsecondary institutions, as well as the methods of assisting in managing the development of professional education system. The results of benchmarking are valuable in planning objectives and strategies to prepare the PSPI educational activities adequately to establish such essential documents as the PSPI Concepts and the PSPI Development Program incorporating the aspects of the educational process.

Modern researchers distinguish couple central types of benchmarking: comparative benchmarking and process-based benchmarking [Voevodina et al. 2009]. 
Comparative benchmarking is the management process in relation to the results of the evaluation and comparison of the operating rate of the institution and its development level. The comparative benchmarking of the professional education system in the Russian Federation cases is based on the comparison of the education process and outcomes of professional training in the postsecondary institutions following several indicators (comparator indicators). Process-based benchmarking allows exploring best practices of institutions for a particular activity for further detailed investigation [Mikhailova, 2008; Rudenko and Dorofeeva, 2013].

Consequently, benchmarking is a process which initially investigates track records of one institution compared to other institutions, competitors and institutions-leaders, and secondly studies and employes the best practices in the particular postsecondary institution activity.

\section{Results and Discussion}

A process-based benchmarking of the professional education system was carried out in the cases of the Russian Federation. According to the results of the National competition "The best project of the professional education system modeling," there is a possibility to recognize the best practices of professional education systems modeling as a result of principles of the project-based approach. Thirty-nine postsecondary institutions of different subjects of the Russian Federation exist among the winners of the competition. They are considered as the most successful and efficient institutions-leaders as the result of process-based benchmarking.

A Fact-finding Questionnaire was developed for postsecondary institutions participated in the contest of their activity results to implement benchmarking in the professional education systems of the Russian Federation subjects. This questionnaire includes 15 questions concerning the benchmarking indicators of the system of professional education in the subjects of the Russian Federation. The Fact-finding Questionnaire allowed determining the best educational practices of postsecondary professional institutions and professional education systems models developed by them.

The first and most significant indicator of the postsecondary professional institution benchmarking is the teachers' perception of the importance of professional education system.

The majority of teachers of PSPI understand the category "professional education system" as a meaningful process which allows developing general competencies, professional and personal qualities valued for students, and also contributing to their enthusiasm to be active in professional sphere to be successfully socialized and business adapted [Moreva, 2001, Kucherova, et al. 2018].
Many PSPI professionals accept the definition proposed by the organizers of the National competition "The best project of the professional education system modeling", that professional education is a meaningful process that contributes to the successful socialization and flexible adaptation of students, and allows measuring abilities of their "Self" up to exacting standards of modern society and professional community, and also forming students' eagerness to self-learn, self-develop, self-educate and self-realize effectively to identify future career, professional values and traditions, and also social and personal implications [Isaev, et al. 2018; Kabayeva, et al 2018].

Consequently, it can be concluded that teachers of postsecondary professional institutions-leaders commonly understand the nature of the professional education system in a similar manner and describe it as an activity allowing to manage the process of students' professional and personal development concerning the precepts of behavior in social and career life, professional and personal self-esteem, and creativeness.

Awareness of the principles and mechanisms of project-based professional education management of postsecondary professional institution students can be mentioned among the most significant indicators of the effectiveness of the professional education system [Dulzon, 2010].

These indicators can be marked on a 10-point scale. Through analyzing the results, it was discovered that the leading postsecondary professional institutions evaluate their knowledge in project management, gaining 7.5 points. The most significant number of postsecondary professional institutions (33\%) estimate this indicator to be 8 points. However, the application of project management in the educational practice of the postsecondary professional institution is estimated at approximately 6.5 points. Also, several postsecondary professional institutions (28\%) assess this indicator to be 5 points. It can be concluded that the perception of project management is essential for the professional education system, PSPI teachers; however, they are not always available to employ this knowledge in the educational process.

Teachers possess methods in training students which allow them to assess the productiveness and efficiency of their activity, which is an essential indicator of the effectiveness of the professional education system in PSPI.

The results reveal that $90 \%$ of the teachers of leading organizations believe that the most comprehensive and objective information about the effectiveness or ineffectiveness of their activities in the context of professional training can be demonstrated by monitoring and diagnostics of students' accomplishments, and also a definite number of postsecondary institutions (21\%) conduct diagnostics additionally to determine whether students and their parents are satisfied. The majority of postsecondary institutions (28\%) evaluate the effectiveness 
of their practice based on the students' learning outcomes. Numerous postsecondary professional institutions (23\%) consider the employers' opinion. All the mentioned methods are employed by a couple of institutions-leaders (Nikologorskiy agro-industrial PSPI, Kurgan state PSPI) to evaluate the effectiveness of the performance of their teaching staff when training the students to be qualified specialists.

One of the significant aspects of benchmarking of the professional education system in the Russian Federation is the analysis of indicators which assist in measuring the professional education and qualification quality level in PSPI. The leading organizations (54\%) are mostly concentrated on the graduates' job placement when assessing the professional education and the quality level of qualification, while others $(41 \%)$ are focused on the students' social training level. Furthermore, for many PSPI $(36 \%)$, the indicator of the professional education and quality level of qualification is the number of winners of the urban, regional, national, and international competitions. Another group of PSPI (33\%) mention such significant indicators as the formation level of students' general and professional competencies and the satisfaction level of educational process; about $18 \%$ of PSPI students' self-government-body activity is the leading indicator, as well as the enrollment of students in the education and social project-based activity; about $10 \%$ of PSPI the students' entrepreneurial activity level is the most important indicator.

However, the major part of teachers evaluating the professional education and qualification quality level in PSPI employ indicators from 1-3 indicators mentioned above. The entire system of indicators is employed by the teaching staff of only one postsecondary institution (Orsha multidisciplinary PSPI named after I.K. Glushkov) to measure the professional education and qualification quality level.

An essential indicator of the productiveness of the professional education system is centered on the inevitable consequences of students' professional training.

According to the outcomes of the analysis, it can be concluded that the principal indicator of professional training of students is the formation level of general competencies and students' personal and profession-based qualities. A variety of PSPI $(62 \%)$ mentions that professional training should be concentrated on the development of general and professional competencies required by the General Education Standard for the top 50. It is required to develop students' personal qualities (hard-working nature, purposefulness, creativeness, economic rationality) and professional abilities (professional ethics, the strength of making responsible decisions, the teamwork ability) [Isaev et al. 2018].

Teachers of PSPI (44\%) believe that the job placement and career development of graduates is additionally an essential outcome of education and professional training.
Furthermore, PSPI teachers (41\%) mention the dynamics of the leading indicators of students' education and socialization process as a consequence of students' professional training; however, another group of PSPI teachers $(28 \%)$ consider it to be the enrollment of students in competitions, championships, and other events. And also the smallest group of PSPI teachers (18\%) are sure that the students' social project-based activity is an important indicator.

Similar postsecondary professional institutions such as Bryansk institution of food and trade, Dimitrovgrad technical institution, Nizhnevartovsk polytechnic institution, Ulyanovsk institution of food and trade consider all the positions as mentioned earlier determining the consequences of students' professional training.

The finding and determining the "best practices" and models of professional training is considered as an essential indicator of the professional training effectiveness in PSPI.

The majority of teachers of educational institutions $(59 \%)$ consider the effectiveness of the practical activity, evidenced by the positive dynamics of professional training indicators alterations, to be a criterion assisting in finding and determining the "best practices" and professional training models in PSPI. This criterion is a diagnostic tool which allows measuring these indicators, and assists in understanding the effectiveness of the educational and training process in PSPI.

A small percentage of educational institutions (36\%) mention the diversity of practice resources (personnel, organizational, financial, material and technical, and methodological) and practice replication in new conditions as an indicator to distinguish the "best practices".

The quantity and quality of professionally-oriented activities organized by the institutions are considered as a criterion to determine the "best practices" and the models of professional education institutions for the third group of PSPI (33\%). The project-based approach management is the most critical indicator for the fourth group of PSPI $(23 \%)$. The novelty, originality, and relevance of the students' practical activity are considered by the fifth group of PSPI (21\%) to be the primary indicator. The data are used concerning the percentage of graduates' job placement and career development for the period of the previous year to determine the primary indicator. The leading indicator from the perspective of the last group of PSPI (18\%) can be the peak effectiveness of professional educational institution related to the number of students-winners of professional skills competitions.

The professionally-oriented innovative educational programs are the criterion for determining the "best practices" and professional education institutions models only for $18 \%$ of PSPI. Seemingly, the program of professional training is one of the most available techniques to investigate strategic guidelines, professional training, fundamental purposes and objectives, innovative 
technologies, forms, and methods of arranging activities for students. This document must remain online.

Finally, the models and practices of professional training are assessed by only $13 \%$ of PSPI according to the employers' opinion and the facts demonstrating strategic partners' enrollment in the implementation of the professional education program.

It can be concluded that comparative benchmarking allows understanding the representatives of professional educational institutions which are mainly focused on the indicators of the effectiveness of other postsecondary professional institutions activity. The best indicators are arranged by the leader institutions in this field. The provided information can be applied to recognize the improvement vector and establish strategic purposes and professional training objectives in a particular PSPI.

The effectiveness of professional training in PSPI is significantly affected by external and internal factors [Demkina, 2011; Vajravelu, 2018].

Over half of the institutions-leaders are assured that the essential external factor affecting the effectiveness of professional training in PSPI is since the employers, social partners and representatives of the business community are engaged in collaborate activity $(51 \%)$. The requirements of the labor market and employment possibilities in the particular business sphere are discussed as another external factor by PSPI (26\%). The economic factor (irrelevance of demands of PSPI graduates and the real economic situation in the society; the economic situation in the family; unfortunate financial situation for teachers; inadequacy of budgetary funds in the region; insufficient funding of PSPI), and also the state policy concerning different areas are emphasized by PSPI (28\%). The impact of the media and the Internet (social networks) is suggested by PSPI (21\%) as well. In general, these external factors can significantly affect all the functions of professional educational institutions, and specifically, postsecondary professional education system.

The analysis of the impact of internal factors of effectiveness of professional training in PSPI indicates that the team activity of teachers, teachers' professional competence level, and supervisors of PSPI is the essential factor of institutions-leaders activity assessment. The education process of students in professional educational institutions are affected by emotional, moral, intellectual characteristics of the teaching staff: appearance, sociability, education level, moral values, professional, and pedagogical culture affect. This internal factor is shown by PSPI (79\%). Simultaneously, the material and technical base and financial status of professional educational institutions are also significant factors for $28 \%$ of PSPI. The impact of socio-cultural environment of PSPI and its specific traditions are considered as an internal factor by $21 \%$ of PSPI, and also the activity, students' motivation, students' self-government-body activity are discussed as significant factors by $3 \%$ of PSPI. Just $10 \%$ of professional educational institutions acknowledge that the best education practices and innovative technologies implementation can be a factor affecting the professional education system.

In general, the impact of several factors are mentioned by the professional educational institutions, and just one of them is highlighted as the most significant infrequently. All these internal factors influencing the effectiveness of professional training in PSPI are considered simply by one educational institution (Tyumen postsecondary professional institution of the food industry, commerce, and service).

A set of the same internal factors and conditions are presented by other professional educational institutions, assisting them in being "the best of the best" in the professional education system.

Assessing the methods and means of the effectiveness of the professional education process of the definite PSPI, and the institutions-participants of the competitions are mentioned as the following:

- Arranging the educational process systematically;

- $\quad$ Staffing level of highly qualified teachers;

- Using project-based management strategy, training employees in project-based management, and implementing social projects;

- Collaborating in a managers team activity, creating task-based activity and implementing strategies;

- Training employees;

- Implementing inclusive education in PSPI;

- Improving material and financial resources, finding outside investments, and collaborating in employers' projects;

- Participating in grant projects, competitions, and innovative activity;

- Holding professional skills competitions, including the WorldSkills standards competitions.

\section{Conclusions}

Benchmarks have been developed to provide evidence on the national standards expected within each curriculum area at every level. They establish clear lines of progression. Their purpose is to make visible what learners need to know and be able to do to progress through the levels and to support consistency in teachers' and other practitioners' professional decisions.

The set of personnel, scientific and methodological, organizational, financial, material and technical conditions allows the definite PSPI conquering the leading positions among the postsecondary professional institutions of the subjects in the Russian Federation. It is required to declare that each institution-leader successfully practices the strategy of project-based management. This experience is of considerable interest to other professional educational organizations in the region and the country. 
In the present research, some benchmarks are suggested and included as follows: joint projects of social partners; to arrange collaborative employers-teachers activity, to hold professional skills developing master classes oriented in technology-based and production-based areas; to hold social events and student councils cooperation; to hold professional skill competitions; to participate in grant projects; to follow new tendencies in the professional area.

\section{REFERENCES}

[1] Demkina, E. V. (2011). Modern approaches to professional education of the future specialist in the educational process. Bulletin of the Adyghe state University. Pedagogy and psychology, 3, 36-41.

[2] Dulzon, A. A. (2010). Project management. Publishing house of Tomsk Polytechnic University, $334 \mathrm{p}$.

[3] Isaev, I. F., Eroshenkova, E. I., \& Krolevetskaya, E. N. (2018). Personality-oriented strategies of students' professional education in higher education institutions. Pedagogical education: challenges of the XXI century: collection of scientific articles of the IX international scientific-practical conference dedicated to the memory of academician V. A. Slastenin, 175-178.

[4] Isaev, I. F., Sitnikova, M. I., Krolevetskaya, E. N., Mikhaylova, D. I. (2018). Diagnostic tools for assessment of the level of college student's upbringing. Belgorod State University Scientific Bulletin. Humanities, 37(3), 508-517.

[5] Kucherova, O. E., Tarasova, S. I., \& Anokhina, S. V. (2018). Professional education of the future specialist in the general system of educational work of colleges of secondary vocational education. Research result. Pedagogy and Psychology of Education, 4(4). URL: http: // rrpedagogy.ru/en/journal/article/1532/

[6] Kabayeva, Z., Mussabaev, S., \& Madalieva, Z. (2018). The formation way of independent Kazakhstan from the individualism and collectivism perspective. Opción, 34(85-2), 706-728.

[7] Kurdyumova, I. M. (2011). The Role of assessment (benchmarking) in the interaction of consumer and producer of innovations in education. Problems of modern education, 5, 79-88.

[8] Mikhailova, E. A. (2008). Fundamentals of benchmarking. Yurist, Moscow, Russia. 214 p.

[9] Malamiri, A., Jahankhah, A., \& Namdar, Sh. (2016). The jurisdiction of the successor in law and jurisprudence Iran. UCT Journal of Social Sciences and Humanities Research, 4(2), 1-9.

[10] Moreva, N. A. (2001). Pedagogy of secondary vocational education. Publishing center Academy, $272 \mathrm{p}$.

[11] Rudenko, M., \& Dorofeeva, A. (2013). Benchmarking Technology. Marketing, 2(129), 57-66.

[12] Voevodina, N. A., Kulagina, A. V., Loginova, E. Yu., \& Tolberg, V. B. (2009). Benchmarking as a tool of the competitive advantage's development. URL: https: //lib.rin.ru/book/benchmarking---instrument-razvitija-konk urentnyh-preimuschestv_elena-loginova/text/

[13] Vajravelu, K. (2018). Innovative Strategies for Learning and Teaching of Large Differential Equations Classes. International Electronic Journal of Mathematics Education, 13(2), 91-95. https://doi.org/10.12973/iejme/2699

[14] Website "National competition" (2019). "The Best project of professional education institution model", URL: https://conspo.bsu.edu.ru. 